\title{
Lightning exposure of oil tanks with changing roof position
}

\author{
A.I. Adekitan \& M. Rock \\ Group for Lightning and Overvoltage Protection, Technische Universität Ilmenau, Germany
}

\begin{abstract}
Crude oil and related petroleum products are major fossil fuels for the supply of energy globally. Floating Roof Tanks (FRTs) are used for storing crude oil after production to ensure product stability before product export, but FRTs are susceptible to lightning strikes. Lightning is a major threat to operational safety in crude oil storage terminals, particular in the tropics with a very high number of thunderstorm days per year $(\mathrm{Td} / \mathrm{yr})$. Protecting crude oil storage tanks against the high-energy lightning current with a continuing current charge of 200 Coulomb requires the design and implementation of a purpose-specific lightning protection system. An evaluation of the probability of a lightning strike to a FRT using the dynamic electro-geometrical model (DEGM) was performed using numerical techniques. The results for the cases considered show that the total probability of a direct strike to the circular tip of the tank shell at its topmost height varies from about $85 \%$ to $99 \%$ depending on the dimension of the tank and the position of the floating roof within the tank.
\end{abstract}

Keywords: Floating roof tank, lightning strike probability, dynamic electro-geometrical model, lightning protection system, lightning current distribution, numerical methods, oil and gas facility, fire, process safety

\section{INTRODUCTION}

Lightning is a natural phenomenon that is as old as the earth itself. Lightning strikes to structures on earth may be very dangerous to facilities, and equipment depending on the level of risk associated with the structure as a function of the geographic location, nature and dimension of the structure, and adjoining facilities. The geographic location determines the number of lightning flashes that the structure is exposed to annually. Lightning strike can either be direct i.e. when the flash terminates on a structure or indirect, when the flash terminates near the structure and connected services. Out of 102 floating roof tank fires studied in China by Ren et al. (2012), it was discovered that $65 \%$ of these were due to direct lightning strikes (Wei et al., 2018). Lightning strike to structures and equipment can result in damage, fire, and even injury to living beings. A lightning flash can either be negative or positive, and fact as shown that about $90 \%$ of lightning flashes are of the negative type while positive flashes carry about six times more current than the negative type (Afa, 2012, Akinyemi et al., 2014).

A number of lightning-induced floating roof tank and facility fire incidents, and equipment damage have occurred across the globe resulting in equipment and facility destruction, expensive repair cost, loss of production time, and man-hours expended on incident reviews. An external floating roof tank has a floating roof that moves with the level of the liquid within the tank in order to limit the vapor space above the liquid crude oil. This helps to reduce the evaporation of light oil fractions and petroleum products by $90-98 \%$ (Kulikov \& Chekardovskiy, 2018). The roofs are made of pontoons which aid the buoyancy of the roof. The gap between the floating roof and the tank shell is covered by rim seals which prevent crude oil from leaking onto the roof. Also, it limits vapor escape from the shell-roof gap. The rim seal region of a floating roof tank is the most likely starting point for a lightning-induced tank fire during a thunderstorm (Chang \& Lin, 2006, Adekitan \& Rock, 2019a). 
Any vapor that escapes from the crude oil during service will bubble to the surface, and escape to the atmosphere through breather valves that are set at atmospheric pressure. High-pressure liquids should not be diverted to a floating roof tank because it can generate sufficient vapor pressure to jam the roof. High crude-oil true vapor pressure (TVP) coupled with inefficient safety barriers from the production end can result in excessive vapor release on the floating roof tank (Adekitan \& Rock, 2019b). The accumulation of escaped flammable vapor around the tank, and the rim seal region can be ignited when lightning strikes.

\subsection{Modes of FRT ignition by lightning}

A floating roof tank can be ignited by lightning in three ways, and these are:

a. Roof surface electrostatic charging due to the charge separation occurring in the clouds which creates a pre-strike electromagnetic field that setup transient currents.

b. When lightning strikes, sparks can easily be generated between intended and unintended gaps existing on the floating roof tank. Sparks can either be a thermal spark resulting from the formation of incendiary materials at a spark point, or a voltage spark that results in the electrical breakdown of air-vapor mixture within the gap.

c. Heating due to the flow of heavy lightning current which can cause thin tank materials that are less than $5 \mathrm{~mm}$ in thickness to melt.

A floating roof tank is a massive structure with a large diameter and tall height, and a gap at the shell-roof interface where flammable fuel vapor may accumulate, and this makes it difficult to design a simple and effective conventional lightning protection system for a floating roof tank. To ensure continuity for the flow of lightning current from the tank shell to the roof during lightning strike, the shell-roof linkage provided by the roof stairs, the use of bypass conductors, and shunts have all been considered, and each has been found to be defective in one way or the order, as they do not continuously provide the optimal low resistance shell-roof connection that can effectively prevent sparks at the rim seal region of the floating roof tank [7]. For example, bypass conductors create dangling cables on the roof, shunts can be easily coated with crude oil which increases its contact resistance. Also, floating roof tank may lose its perfect roundness over time, or when tank subsidence occurs the shunts become disconnected from the tank shell creating a gap it was installed to prevent.

A device called a retractable grounding array (RGA) was developed in order to address the issues created by the extensive length of bypass cables. RGA is made of retractable weaved cable strands that adjust its length based on the position of the roof. Although the RGA may be better than the bypass cable which conducts the continuing, and the intermediate components of the lightning current by ensuring minimal length at any roof position (Hu \& Liu, 2012), but its sufficiency as a replacement for shunts which are meant to conduct the fast (rising) lightning current pulse needs to be determined. Also, due to continuous extension and retraction of the RGA with the changing floating roof position, a number of RGAs tend to snap off from the roof over time, as observed on some tanks. The roof of the floating roof tank constantly changes its vertical position within the tank based on the level of the liquid content, and as such, the portion of the roof exposed to direct lightning strike varies depending on the position of the roof.

Currently, there is no approved air termination design based on conventional lightning protection system for FRT. This is due to the intricacies of how direct and indirect lightning strikes interact with FRT. In this study, the interaction of lightning with FRT is investigated by evaluating the probability of lightning strikes to different points on a FRT using the dynamic electro-geometrical model. Based on the result of the numerical model, an air termination configuration that can adequately intercept and safely dissipate the high energy lightning current while preventing sparking at the shunt-shell interface can now be developed. 


\section{MATERIALS AND METHODS}

The methodology applied in this study has three key aspects. First, a volume from which lightning can strike a FRT is defined as the attractive volume as discussed in section 2.1, while section 2.2 highlights the details of a numerical model termed the dynamic electro-geometrical model (DEGM) for computing the probability of a direct lightning strike to structures within the defined volume. Finally, the DEGM model is applied to various dimensions of a FRT as described in section 2.3.

\subsection{The attractive volume of a FRT}

The risk of a lightning strike to a structure can be evaluated using the concept of the attractive volume. The attractive volume defines a space volume around a structure to be protected within which lightning strikes can hit the object. The object is deemed naturally protected from all lightning downward leaders which do not enter the attractive volume of the protected object. The concept was developed to explain the stochastic nature of the descent of a downward leader, and the orientation point at which the object to be struck by lightning is determined (Horváth, 1991). The distance between the orientation point, and the object to be struck or the ground is known as the striking distance. It is a function of the lightning-induced electrical field strength on the ground, and this also depends on the magnitude of the electric charge in the lightning leader channel.

By applying increasing striking distance, various rolling sphere radii that can touch the FRT and the ground were computed, the centers of such spheres as shown by the curved black line in Figure 1 represent the boundary of the interception volume of the FRT on the "right" side of the structure. The same concept applies on all sides around the structure, and this will generate a volume within which downward leaders can orientate towards the floating roof tank.

\subsection{The dynamic electro-geometrical model (DEGM)}

The peak value of lightning current has been measured and recorded at different regions of the world, and this has been used to develop a distribution function for the striking distance (r) using logarithm normal functions (Horváth, 2006). In terms of the striking distance, the probability density function (PDF) is defined by Equation 1. By applying the median value of lightning current distribution and the standard deviation for positive and negative lightning, the distribution obtained is shown in Figure 2. Also, the effective probability distribution

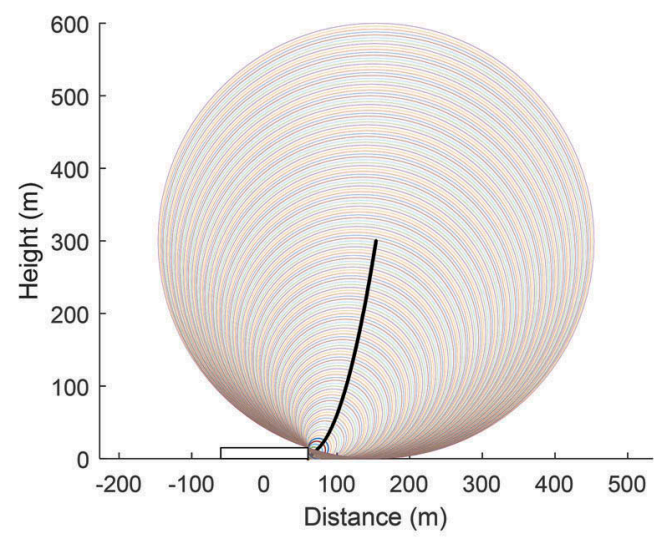

Figure 1. Interception boundary at one side of FRT. 


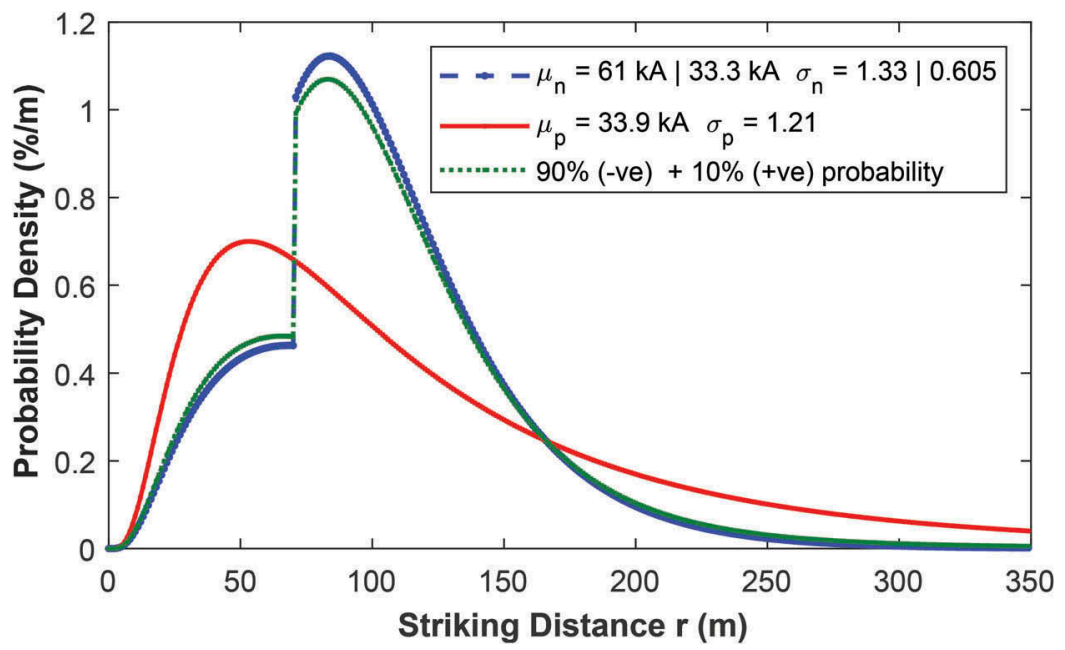

Figure 2. Striking distance probability density (blue, $\mathrm{n}-$ negative lightning, red, $\mathrm{p}-$ positive lightning).

resulting from the summation of $90 \%$ of the PDF for negative lightning and $10 \%$ for positive lightning is also plotted in comparison in Figure 2. From lightning observations over time, about $90 \%$ of all lightning strikes have negative polarity, and as such, the effective probability distribution will be applied in the numerical computation of the dynamic electro-geometrical model (Hannig et al., 2014).

The DEGM applies the concept of probability weighted collection volume (Horváth, 2006), which modulates collection volume by the probability density function i.e. the striking distance density. To apply the DEGM concept to a floating roof tank (FRT), the surface of the FRT is first discretized into various surface points, and the associated interception volume enclosed by the circle centers as shown in Figure 1 is also discretized into multiple orientation points from which lightning can orientate towards the FRT. For each orientation point in space, the distance to various points on the FRT is computed, and the point(s) on the FRT having distances equal to the lowest geometric distance are determined as the final strike point(s) from that specific orientation point in space above the FRT (Adekitan \& Rock, 2020). The associated probability is computed using Equation 1, and the process is repeated for all the orientation points within the interception volume. The probability of a strike to the same point on the FRT from different orientation points is cumulated. Finally, the overall probability for all the points on the FRT is summed, and from this value, the percentage of the probability of a strike for each point on the FRT can be computed. This is a numerical computation which has also been applied by Kern et al. (Kern et al., 2010) for various structures.

$$
P D F(r)=\frac{10^{\frac{-1}{0.65}}}{0.65} r^{\frac{0.35}{0.65}} \frac{1}{\sigma\left(\frac{r}{10}\right)^{\frac{1}{0.65}} \sqrt{2 \pi}} e^{-\left\{\ln \frac{\left(\frac{r}{10}\right)^{\frac{1}{0.65}}}{\mu}\right\}^{2}}{ }^{2 \sigma^{2}}
$$

Where $r$ is the striking distance, $\mu$ is the median value and $\sigma$ is the standard deviation $(\sigma)$ of the lightning current distribution.

\subsection{Numerical simulation of various FRT dimensions and roof positions}

Large floating tanks are more susceptible to lightning induced ignition and fires. This is due to the increased surface area that is exposed to direct lightning strikes, and the consequences 
of indirect strikes as charges accumulate on, and around the tank. The position of the floating roof changes within a FRT based on the level of the liquid in the tank. Due to the changing roof position, the exposed area of the roof that can be struck by lightning from above the tank, and within the interception volume of the FRT i.e. cloud-to-ground strikes (Wang et al., 2018), varies with the position of the roof (Adekitan \& Rock, 2019b).

In this study, the effect of tank height and the position of the roof within the tank on the probability of lightning strike to different points on a FRT is examined. Three different tank heights were considered; $10 \mathrm{~m}, 15 \mathrm{~m}$, and $20 \mathrm{~m}$ high FRTs with a diameter of $60 \mathrm{~m}$. The roof positions were simulated to determine the effect of changing roof position. The first roof position is at the top, when the roof is most exposed to direct lightning strikes. The middle position, at half the height of the tank was also considered, and the bottom position which for this simulation was set at $0.5 \mathrm{~m}$ from the ground. Usually, the roof does not get to $0 \mathrm{~m}$ on the ground. At the base of the tank, the roof sits on adjustable legs, that may be as high as $2 \mathrm{~m}$ to allow for man-entry for maintenance checks.

\section{RESULTS AND DISCUSSION}

The results of the numerical analysis for the various roof positions are presented in this section.

In Figure 3, the floating roof of the $30 \mathrm{~m}$ radius tank with $20 \mathrm{~m}$ in height is at the topmost position, and at this point, the roof has the highest exposure to direct lightning strikes. In Figure 4 , the roof is at half the height of the tank and only a small portion of the tank roof

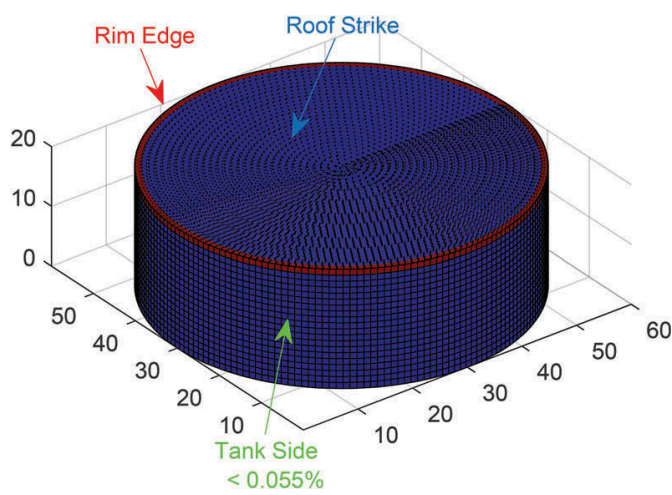

Figure 3. Floating roof at the highest position within the tank.

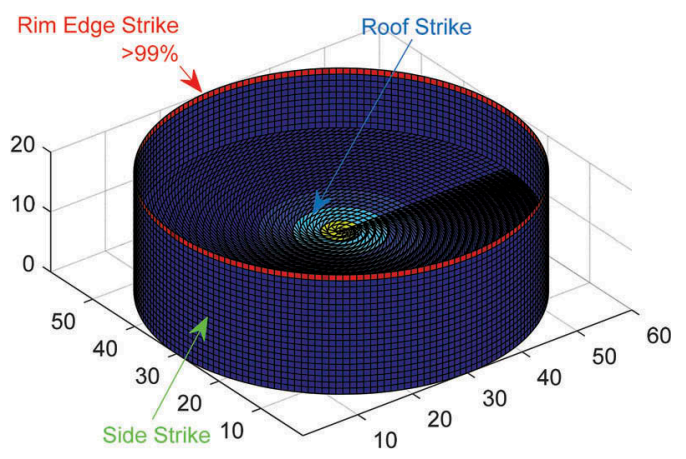

Figure 4. Floating roof at the middle height of the tank. 
around the center is exposed to direct cloud-to-ground strikes. In Figure 5, the roof is shown at the base of the tank, and at this position the risk of a direct lightning strike to the roof is extremely small.

The surface of the FRT is categorized into three: the roof, the rim edge which refers to the topmost circular portion of the cylindrical tank shell, and the side of the tank which encompasses the remaining cylindrical wall of the tank below the rim edge. The probability of a strike to each of these three parts is presented for the $10 \mathrm{~m}, 15 \mathrm{~m}$, and $20 \mathrm{~m}$ high FRT in Figure 6, Figure 7, and Figure 8 for the various roof positions (top, middle, and bottom).

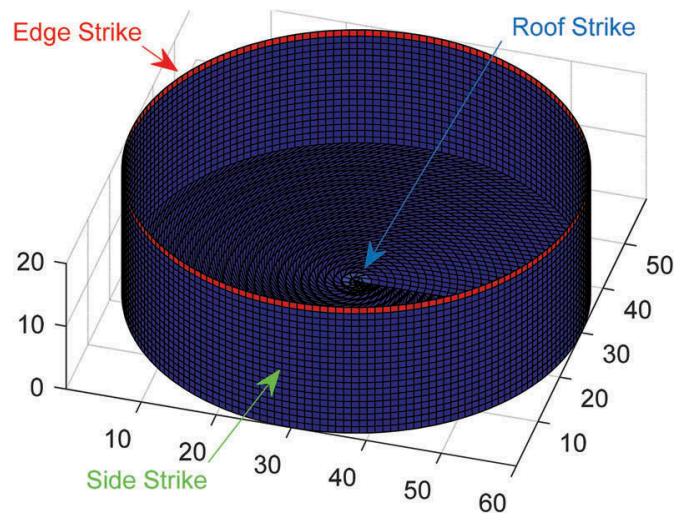

Figure 5. Floating roof at the base of the tank.

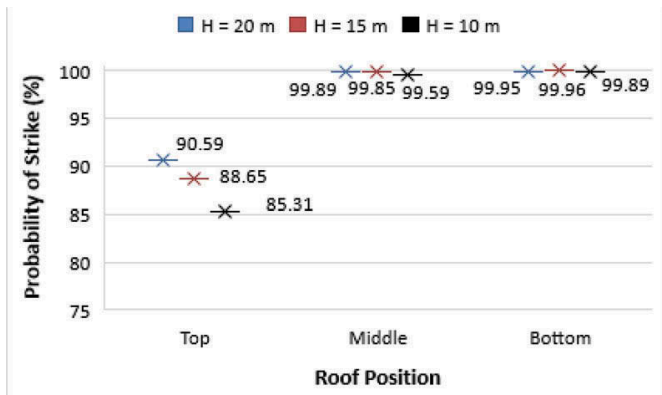

Figure 6. Probability of a lightning strike to the rim edge of the tank cylinder.

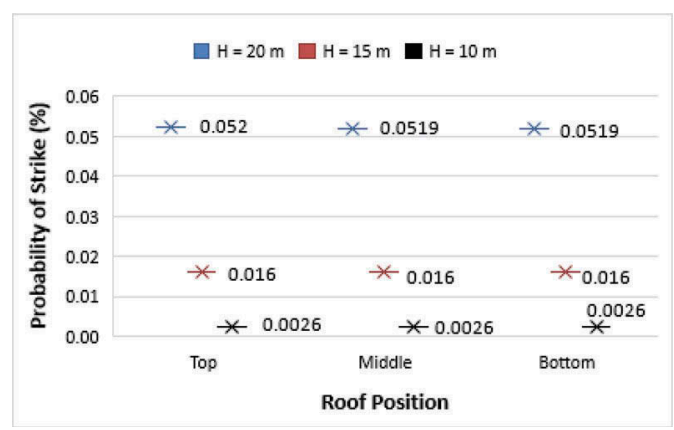

Figure 7. Probability of a lightning strike to the side of the tank. 


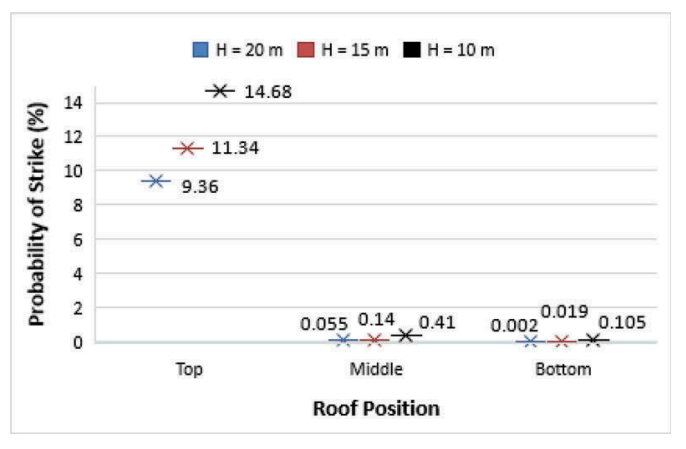

Figure 8. Probability of a lightning strike to the roof of the FRT.

The probability of a lightning strike to the rim edge of the tank cylinder for the three different tank heights considered is shown in Figure 6. It was observed that the probability of a strike to the rim of the cylindrical tank shell increased with tank height at the topmost roof position. At other roof positions i.e. midway, and at the bottom, the probability of a strike to the rim edge is greater than $99 \%$, and this did not change significantly with tank height.

As shown in Figure 7, the probability of a strike to the remaining part of the tank cylindrical shell referred to as tank side increases with tank height (i.e. more exposed tank wall surface area), but the probability of a strike is relatively constant with changing roof position.

For the floating roof as shown in Figure 8, the probability of a direct lightning strike reduces with increasing tank height when the roof is at the topmost height. At the middle position, the probability of a strike to the roof reduces slightly with increasing height, and at the bottom, the probability of a strike is relatively constant irrespective of tank height.

The highest probability of a direct strike occurs when the roof is at the topmost position. The probability of a direct strike to the rim edge, i.e. the rim-seal area of the tank where shunts are positioned, with a high probability of flammable vapor presence is highest as compared with the risk of a strike to the side of the tank or the floating roof. When heavy currents flow through the shunt-shell contact within the rim-seal region, the risk of spark formation is high. Hence, it is necessary to ensure that lightning currents flowing down to the rim edge is minimal. This may be achieved by using interconnected, parallel air termination arrangements, which create multiple flow paths for the lightning current and associated energy. This cannot be achieved by using vertical air termination rods on the FRT shell that will only intercept strikes and conduct the full currents down to a single point on the tank shell.

From the simulated results, the frequency of lightning strike $\left(N_{i}\right)$ can be computed for the rim edge, the roof, and the side of the tank by applying Equation 2.

Frequency of lightning strike $\left(N_{i}\right)=$ ground flash density $\left(N_{G}\right) \times$ probability modulated collection volume $(C P)$

$$
N_{i}=N_{G} \times C P
$$

Where $N_{G}$ is the ground flash density in flashes $/ \mathrm{km}^{2} / y e a r$, and $C P$ is the computed probability using DEGM for the rim seal, the roof, and the side of the tank. Assuming, the tank is located in the Niger Delta region of Nigeria; the analysis is therefore based on a ground flash density of 16 flashes $/ \mathrm{km}^{2} /$ year. The estimated frequency of a lightning strike to the three categorized areas of the FRT is computed for the different tank heights and roof positions. The result is presented in Table 1 for the $10 \mathrm{~m}$ high FRT, Table 2 for the $15 \mathrm{~m}$ high FRT, and Table 3 for the $20 \mathrm{~m}$ high FRT. The variation in the estimated frequency of lightning strikes for the different roof positions is because of the changing total exposed area of the FRT that is susceptible to direct lightning strike as the roof changes position. 
Table 1. The frequency of lightning strike per year for the $10 \mathrm{~m}$ high FRT.

\begin{tabular}{llll}
\hline & Rim Edge & Side Wall & Roof \\
\hline Top & 0.2479 & 0.000008 & 0.0427 \\
Middle & 0.2929 & 0.000008 & 0.0012 \\
Bottom & 0.2943 & 0.000008 & 0.0003 \\
\hline
\end{tabular}

Table 2. The frequency of lightning strike per year for the $15 \mathrm{~m}$ high FRT.

\begin{tabular}{llll}
\hline & Rim Edge & Side Wall & Roof \\
\hline Top & 0.3336 & 0.00006 & 0.0427 \\
Middle & 0.3796 & 0.00006 & 0.0005 \\
Bottom & 0.3802 & 0.00006 & 0.0001 \\
\hline
\end{tabular}

Table 3. The frequency of lightning strike per year for the $20 \mathrm{~m}$ high FRT.

\begin{tabular}{llll}
\hline & Rim Edge & Side Wall & Roof \\
\hline Top & 0.4129 & 0.00024 & 0.0427 \\
Middle & 0.4593 & 0.00024 & 0.0003 \\
Bottom & 0.4596 & 0.00024 & 0.0000 \\
\hline
\end{tabular}

\section{CONCLUSIONS}

The risk of a strike to various points on a floating roof tank (FRT) is dynamic, and it is influenced by the position of the roof within the tank. The dimension of a FRT plays a significant role in the manner of exposure of such tanks to direct lightning strikes. The dynamic electrogeometrical model simulations carried out in this study reveals that the height of a FRT and the position of the floating roof determines the risk of a direct lightning strike to the roof. The numerical simulation shows that when the roof is at the uppermost point, the risk of a strike to the rim edge (around the rim seal region) where flammable vapor concentration is often present, increases with increasing tank height for the same diameter tank. As the roof descends into the tank, the probability of a lightning strike to the rim edge increases with reducing roof height. By the time the roof is at half the height of the tank, the probability of a strike to the rim edge of the tank shell is around $99 \%$.

In line with the realities of the result of this simulation, conventional air terminations positioned on the FRT must be designed, not only to be able to intercept lightning strikes e.g. by using air termination rods, but also, it must be able to divide the lightning current into multiple flow parts in order to reduce the risk of sparking when the current gets to the rim seal region of the tank shell where arcing may occur at the shunt-shell region. This study as revealed the likelihood of lightning strikes to various parts of a FRT with respect to floating roof position. The knowledge provided here, will serve as bases for the design and investigation of various conventional air termination arrangements for reliably protecting a FRT from direct strikes while also preventing arcing at the rim-seal region.

\section{ACKNOWLEDGMENT}

This is to appreciate the support of the Nigerian Petroleum Technology Development Fund (PTDF) through the Overseas Scholarship Scheme in partnership with the German Academic Exchange Service (DAAD). 


\section{REFERENCES}

Adekitan, A. I. \& Rock, M. 2019a. Lightning induced fires: A case study of floating roof tanks. XII Russian-German Raw Materials Forum: Youth Day, St Petersburg, Russia. Saint-Petersburg Mining University, 156-157.

Adekitan, A. I. \& Rock, M. 2019b. Performance investigation of Lightning Protection Systems for Floating Roof Tanks in Nigeria. 13. VDE Blitzschutztagung, 24. - 25. Oktober 2019 Aschaffenburg. VDE Fachberichte, 71-77.

Adekitan, A. I. \& Rock, M. 2020. The impact of space point definition on dynamic electro-geometrical model of lightning strike probability. Electric Power Systems Research.

Afa, J. T. 2012. Lightning Activities and Ground Flash Density in Niger Delta Coast. Journal of Engineering and Applied Sciences, 7, 339-341.

Akinyemi, M., Boyo, A., Emetere, M., Usikalu, M. \& Olawole, O. 2014. Lightning a Fundamental of Atmospheric Electricity. International Conference on Environment Systems Science and Engineering, $47-52$.

Chang, J. I. \& Lin, C. 2006. A study of storage tank accidents. Journal of Loss Prevention in the Process Industries, 19, 51-59.

Hannig, M., Hinrichsen, V., Hannig, R., \& Brocke, R. 2014. An analytical consideration on the striking probability and the total amount of strikes to simple structures according to standardized regulations. 32nd International Conference on Lightning Protection (ICLP). IEEE.

Horváth, T. 1991. Computation of lightning protection. Cargese Lectures in Physics.

Horváth, T. 2006. Interception of lightning air termination systems constructed with rolling sphere method. Proc. 28th International Conference on Lightning Protection (ICLP).

Hu, H. \& Liu, Q. 2012. Research on lightning sparks discharge and protection measures of large floating roof tank. 31st International Conference on Lightning Protection (ICLP). IEEE, 1-4.

Kern, A., Schelthoff, C. \& Mathieu, M. 2010. Probability of lightning strikes to air-terminations of structures using the electro-geometrical model theory and the statistics of lightning current parameters. 30th International Conference on Lightning Protection (ICLP). IEEE.

Kulikov, A. M. \& Chekardovskiy, S. M. 2018. Improving the safety of operation of tanks with a floating roof in the winter period. IOP Conference Series: Materials Science and Engineering, IOP Publishing, 445012010.

Ren, X., Fu, Z., Yan, N., \& Sun, W. 2012. Analysis and experimental investigation of direct lightning protection for floating roof oil tanks. Electric Power Systems Research, 94 134-139.

Wang, C., Sun, Z., Jiang, R., Tian, Y. \& Qie, X. 2018. Characteristics of downward leaders in a cloud-toground lightning strike on a lightning rod. Atmospheric Research, 203, 246-253.

Wei, T., Qian, X., \& Yuan, M. 2018. Quantitative risk assessment of direct lightning strike on external floating roof tank. Journal of Loss Prevention in the Process Industries, 56, 191-203. 